\title{
Plant Glutathione Transferases: Structure, Antioxidant Catalytic Function and in planta Protective Role in Biotic and Abiotic Stress
}

Evangelia Chronopoulou ${ }^{1}$, Kassiani Kontouri ${ }^{1}$, Marianna Chantzikonstantinou ${ }^{1}$, Fotini Pouliou ${ }^{1}$, Fereniki Perperopoulou ${ }^{1}$, Georgia Voulgari ${ }^{2}$, Eirini Bosmali ${ }^{3}$, Irene Axarli ${ }^{1}$, Irini Nianiou-Obeidat ${ }^{2}$, Panagiotis Madesis ${ }^{3}$, Athanasios Tsaftaris ${ }^{3}$ and Nikolaos E. Labrou ${ }^{1 *}$

\author{
${ }^{1}$ Laboratory of Enzyme Technology, Department of Agricultural Biotechnology, Agri- \\ cultural University of Athens, Iera Odos 75, 11855-Athens, Greece; ${ }^{2}$ Department of \\ Genetics and Plant Breeding, School of Agriculture, Aristotle University of Thessalo- \\ niki, P.O. Box 261, Thessaloniki GR-54124, Greece; ${ }^{3}$ Institute of Applied Bioscience, \\ CERTH, 6th km Charilaou-Thermis Road, P.O. Box 361, Thermi GR-57001, Thessa- \\ loniki, Greece
}

\begin{abstract}
Plant cytosolic glutathione transferases (GSTs) belong to an ancient enzyme superfamily with multiple and diverse functions which are important in counteracting biotic and abiotic stress. GSTs catalyze the conjugation of xenobiotics and endogenous electrophilic compounds with glutathione (GSH), leading to their detoxification. GSTs not only catalyze detoxification reactions but they are also involved in GSH-dependent isomerization reactions, in GSH-dependent reduction of organic hydroperoxides, biosynthesis of secondary metabolites, and exhibit thioltransferase and dehydroascorbate reductase activity. The applications of 'omics' technologies have allowed the classification of GSTs and the study of their evolution and sequence diversity, while enzymology has provided powerful insights into their catalytic role. This review focuses on plant GSTs, and attempts to give an overview of the new insights into their catalytic function and biological role in biotic and abiotic stress tolerance mechanisms in plants.
\end{abstract}

Keywords: Glutathione transferase, herbicide detoxification, biotic stress, abiotic stress.

\section{INTRODUCTION}

GSTs are ubiquitous enzymes in aerobic organisms and are encoded by large gene families of cytosolic, mitochondrial, and microsomal proteins. GSTs mainly catalyse the conjugation of reduced glutathione ( $\gamma$-L-Glu-L-Cys-Gly; GSH) via the sulfhydryl group, to electrophilic centres on a wide variety of compounds, both endogenous and xenobiotic [1-4].

The tripeptide GSH is mostly present in reduced form (GSH), while the oxidized form

\footnotetext{
*Address correspondence to this author at the Laboratory of Enzyme Technology, Department of Agricultural Biotechnology, Agricultural University of Athens, Iera Odos 75, 11855-Athens, Greece; Tel: +30 (210) 5294308;

Fax:+30 (210) 5294308; E-mail: lambrou@aua.gr
}

(GSSG) is a marker of oxidative stress [5-8]. Under physiological conditions, free GSH is present in concentrations ranging from 1 to $10 \mathrm{mM}[6,7]$. The distribution of GSH is significantly different between gametophyte and sporophyte. Gametophyte is equally distributed among mitochondria, plastids, nuclei and the cytosol, while in sporophyte the highest concentration was found in mitochondria followed by nuclei, the cytosol, peroxisomes and plastids. High levels of GSH in mitochondria are essential for the proper plant development [9].

The conjugation of GSH to xenobiotics serves several important roles: (a) limit and restrict the reactivity of the chemicals; (b) increases their solubility and facilitates their membrane transport 
from the cell and organism; and (c) in some cases, it leads to the formation of secondary metabolites or essential biological mediators [1, 10].

The soluble GSTs have an ancient monophyletic origin shared with the respective enzymes from nearly all eukaryotic and prokaryotic species [10]. The Cytosolic GSTs from mammalians, insects, plants, and bacteria comprise a complex enzyme superfamily that has been subdivided into a number of classes based on a variety of criteria (e.g. amino acid/nucleotide sequence, and immunological, kinetic and structural properties) [11]. GST genes and proteins from mammalian sources have been well characterized, but studies of GSTs from non-mammalian sources such as plants and microorganisms have revealed the existence of several different classes (for more details see Sheehan et al., 2001 [11]). For example, the soluble GSTs of vascular plants according to their can be subdivided into the following distinct classes: phi $(F)$, tau $(U)$, zeta $(Z)$, theta $(T)$, lambda $(\lambda)$, dehydroascorbate reductase (DHAR), EF1B $\gamma$ and tetrachlorohydroquinone dehalogenase (TCHQD) [4, 10-19]. Two new classes, $l$ (iota) and hemerythrin have been found in the moss Physcomitrella patens [16]. The majority of the plant GSTs are classified as tau (GSTU) and phi (GSTF). The DHAR class is essentially present in terrestrial plants, while is absent in cyanobacteria and a single gene, that likely represents the ancestor DHAR gene, is found in a few algae of the Chlorophyceae and Trebouxiophyceae classes [20].

GSTs are promiscuous enzymes capable of catalyzing the conjugation of GSH with a broad range of electrophilic substrates [21-25]. This functional promiscuity of GSTs correlates with structural flexibility, which allows for recognition of diverse structures at minimal energetic cost [26]. GSTs exhibit wide substrate specificity toward electrophile molecules including organic halides, organic hydroperoxides, epoxides, arene oxides, $\alpha$ - and $\beta$-unsaturated carbonyls, organic nitrate esters, and organic thiocyanates [24]. GSTs not only catalyze the conjugation of GSH to electrophilic compounds but they also have more functions, including double-bond cis-trans isomerization, dehydroascorbate reduction and binding "ligandin" activity [25]. For example, some members (zeta class) are involved in GSH-dependent isomerization reactions (e.g. in GSH-dependent isomerization of maleylacetoacetate to fumarylacetoacetate), in the synthesis of sulfur-containing secondary metabolites such as volatiles and glucosinolates, and the conjugation, transport and storage of reactive oxylipins, phenolics and flavonoids [10]. In addition, Lo Piero et al., (2006) have reported the involvement of GST from Citrus sinensis $L$. in anthocyanin glutathionylation [27]. Typical GST-catalyzed reactions are schematized in (Fig. 1).

GSTs can be found in plants from early embryogenesis to senescence [17]. They play a crucial role in the protection of cells from a wide range of biotic and abiotic stresses, including pathogen attack, xenobiotic and heavy metal toxins, oxidative stress and UV radiation [28-31]. The diversity of potential xenobiotics and stressors, causes functional divergence of this enzyme family which has major adaptive significance. Therefore, the supergene GST family shows extensive functional diversity in gene expression, enzymatic activities, and substrate specificities [17]. Their role in stress tolerance in plants is less characterized than their detoxification function [32], however, GSTs are thought to be evolved as part of the cell protection system against oxygen toxicity [33, 34]. The antioxidant catalytic function of GSTs [14] is displayed through peroxidase [35], thioltransferase and dehydroascorbate reductase activity [32, 36] (Fig. 2). Recently, in silico analysis revealed that GSTs might be subjected in post translational regulation [37].

Proteins able to participate in unrelated biological processes have been grouped under the generic name of moonlighting proteins [38, 39]. Work with different organisms has uncovered a great number of GST isoenzymes that are able to participate in unrelated biological processes. In addition to their role in catalyzing the conjugation of electrophilic substrates to GSH, these enzymes also carry out a range of other functions. Different activities of GST isoenzymes include their role as modulators of signal transduction pathways that control cell proliferation and cell death, regulation of the metabolic pathways, bind non-catalytically and transfer a wide range of endogenous and exogenous ligands [10, 11, 40-42]. 


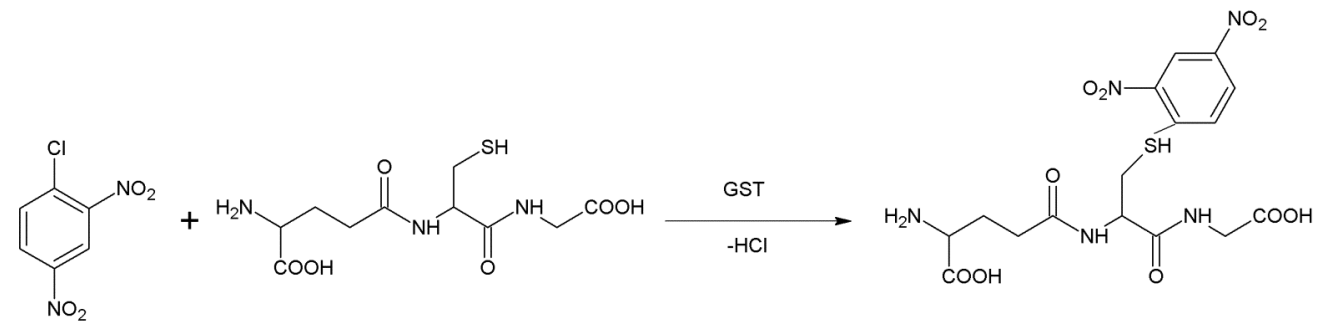

(A)

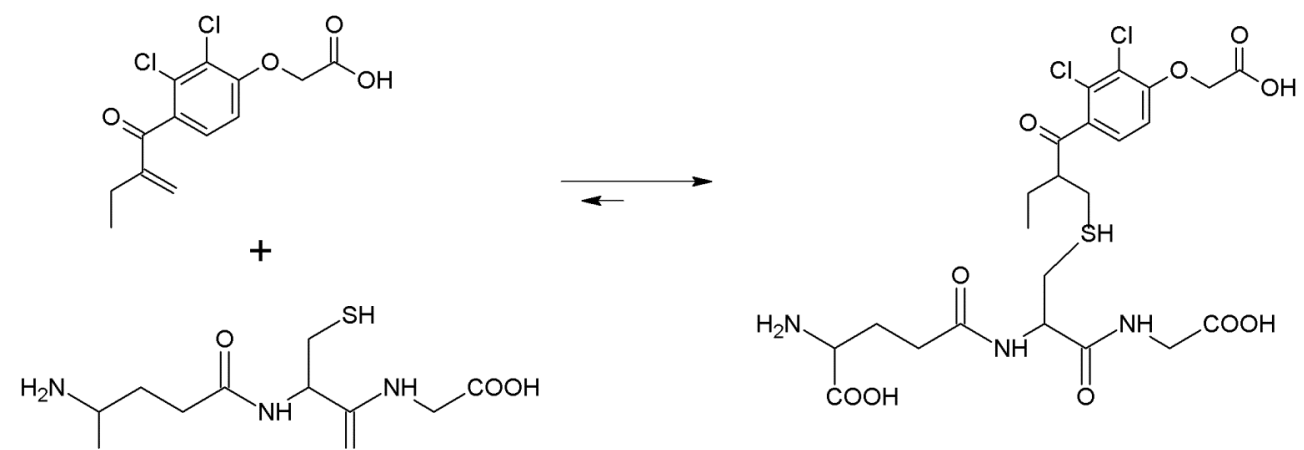

(B)
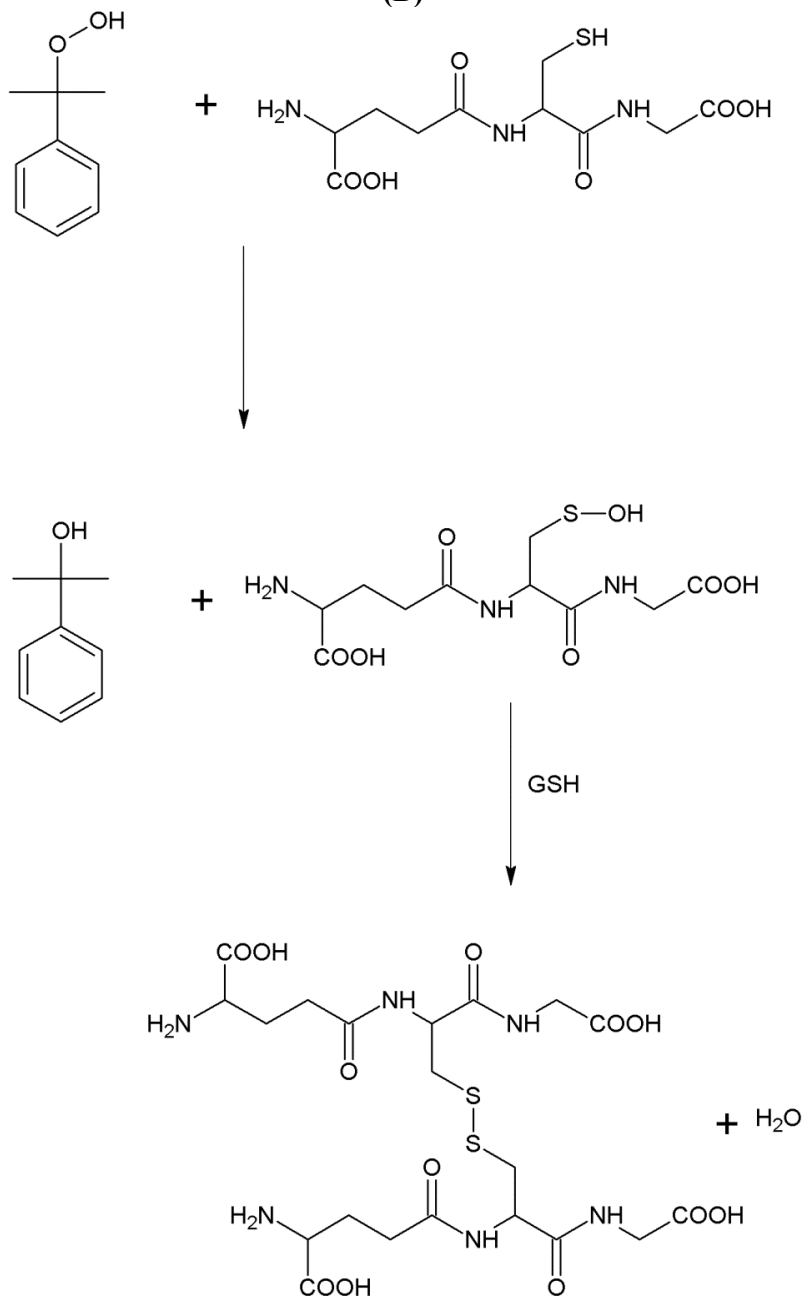

Fig. (1). Typical GST-catalyzed reactions. (A): nucleophilic aromatic substitution with 1-chloro-2,4-dinitrobenzene, (B): Michael-type addition reaction with ethacrynic acid, (C): hydroperoxide reduction with cumene hydroperoxide. 


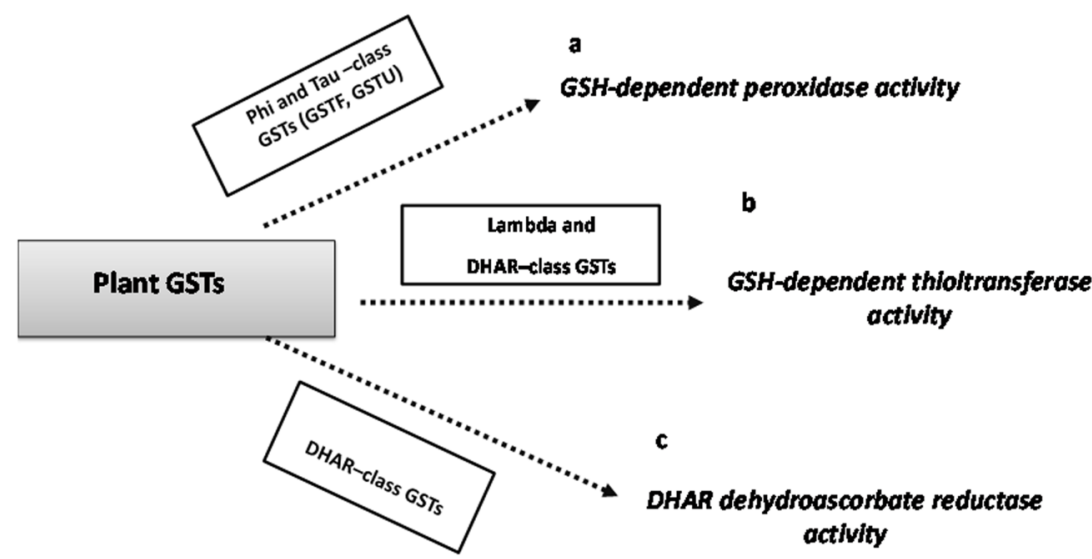

Fig. (2). Catalytic activity in relation to the antioxidant function of GSTs: a) peroxidase activity, b) GSH-dependent thioltransferase activity, and c) dehydroascorbate reductase activity.

For example, the isoenzyme GSTP1-1 from human is an ubiquitously expressed protein that plays an important role in the detoxification and xenobiotics metabolism. This isoenzyme, has been associated with the development of tumor resistance to anticancer drugs, acts as a repressor of JNK and other protein kinases involved in stress response, cell proliferation, and apoptosis, and plays an important regulatory role in TNF- $\alpha$ induced signaling by forming ligand-binding interactions with TRAF2 [43, 44]. Another example of moonlight activity comes from the protein Ure2 [45]. Ure 2 is an important regulator of nitrogen catabolite repression, the process that controls the utilization of available nitrogen sources by $S$. cerevisiae. Ure2 does not have a typical GST substrate specificity but belongs to a subset of GST proteins that exhibits glutathione peroxidase activity and are active against different oxidants [46].

\section{ANTIOXIDANT CATALYTIC FUNCTION OF GSTs}

GSH can function as an antioxidant and as a substrate or cofactor of GSTs [12, 47-52]. GSH is mainly known for its antioxidant function against Reactive Oxygen Species (ROS) and hydrogen peroxide $\left(\mathrm{H}_{2} \mathrm{O}_{2}\right)[53,54]$. The high concentration of ROS can lead to a non-controlled oxidation of DNA, proteins and membrane lipids which can cause disruption of metabolism and cellular structure destruction $[52,55]$. Plant GSTs of tau and theta classes exhibit GSH-dependent peroxidase activity (GPx, EC 1.11.1.9) [35, 56] and act protectively against cytotoxicity by reducing organic hydroperoxides of fatty acids and nucleic acids to monohydroxyalcohols which are less toxic $[1,15$, 36]. This reaction is important as prevents the formation of cytotoxic aldehyde derivatives from organic hydroperoxides degradation [15]. Plant GSTs with GPx activity contribute to defence against oxidative injury during various stresses, including oxidative stress, pathogen attack, herbicide treatment, and to abiotic stresses [57]. It was suggested that in addition to the direct protective effect of the GPx activity, the enhanced tolerance may be due to the GPx-mediated increase in GSSG concentration in the cells, which then function as a signal to activate further protective stress responses [58-60].

The GPxs in plants can be divided into three types. These are the selenium-dependent GPxs [61], the non-selenium dependent phospholipids hydroperoxide glutathione peroxidases (PHGPxs), and glutathione transferases showing glutathione peroxidase activity [62]. The selenium-dependent GPxs composed of four $16 \mathrm{kDa}$ subunits, contain selenocysteine at the catalytic site and appears to be similar to mammalian cytosolic GPx. PHGPx contain cysteine at the catalytic site and appears to be different to the mammalian type PHGPxs. These enzymes can be widely found in plant cells including chloroplasts, mitochondria, cytoplasm, peroxisome and apoplast [62-64].

Plant theta and tau class GSTs exhibit high GPx activities toward organic hydroperoxides [65]. For example, the isoenzymes from wheat [28], peas [13], soybean [66], monocot weeds such as Alopecurus myosuroides (blackgrass), and dicot weeds such as Arabidopsis thaliana [62, 67] display wide substrate specificity towards organic 
hydroperoxides. In particular, the phi and tau class GSTs from Arabidopsis thaliana have shown high peroxidase activity with linoleic acid hydroperoxides (13-hydroperoxy-9,11,15-octadecatrienoic acid and 13-hydroperoxy-9,11-octadecadienoic acid) [67].

The isoenzymes of the GST-like class with dehydroascorbate reductase (DHAR) activity catalyze the reduction of dehydroascorbate (DHA) to ascorbic acid using_GSH. Members of this class have already been found in Arabidopsis [14], rice and soybean [32]. The DHARs do not exhibit GSH conjugating activity. Unlike most other GSTs, DHARs are monomeric and form mixed disulfides with GSH [14].

Members of the lambda and DHARs classes of GSTs, exhibit thioltransferase activity using the 2hydroxyethyl disulfide (HED) as a substrate [14]. In cases of oxidative stress, when there is a lack of GSH, some protein thiols are S-thiolated making protein-thiol disulfides (Fig. 3). This modification affects the activity of the proteins or enzymes. Whereas many proteins are active when the key sulfhydryls are in the thiol form, others require them to be in the oxidized, disulfide form $[68,69]$. For example, glutathione disulfide (GSSG) can activate enzymes such as glucose-6-phosphatase, acid phosphatase, $\gamma$-aminolaevulinate synthetase, creatine kinase, etc. On the other hand, GSSG inhibits glycogen synthetase, pyruvate kinase, adenylate cyclase, phosphorylase/phosphatase, ribonucleotide reductase, phosphofructokinase, etc $[15,68,70-72]$.

The involvement of elevated GST expression as a marker for plant response to herbicide stress is continuously gaining ground. GST enzymes can play both a direct role (detoxification of herbicides by GSH conjugation) and an indirect role (in- volvement in stress response) in the mechanism of herbicide resistance [4, 73-76].

\section{STRUCTURE OF GSTs}

GSTs belong to the thioredoxin superfamily (also including thioredoxin, glutaredoxin, and disulfide-bond formation facilitator) classified by the common GSH binding domain-adopted thioredoxin fold (Fig. 4) [77, 78]. So far, the available three-dimensional (3D) that have been solved can be summarized as follows: (i) one phi class GSTs from Arabodopsis thaliana [79], two from maize (ZmGSTF1 and ZmGSTF3) [80, 81], (ii) a zeta class GST from Arabodopsis thaliana [82], (iii) and five tau class GSTs, one from wheat ( $T a \mathrm{GSTU} 4)$ active in herbicide detoxification [30], one from rice (OsGSTU1), and three from Glycine max (GmGSTU4-4) [83-85]. Recently the structures of two isoenzymes from Populus trichocarpa that belong to lambda class have been reported [86]. Because of the important role of the tau class GSTs, the structure of the GmGSTU4-4 [83, 84] will be presented and discussed with regards to the other plant classes.

\subsection{Overall Structure}

Each soluble GST is, in general, active as dimer of approximately $23-30 \mathrm{kDa}$ subunits of and an average length of 200-250 aminoacids [79-86] (Fig. 4). Sequence identity within class is typically $>40 \%$. For example, sequence identity within tau class GSTs is shown in (Fig. 5A). Interclass identities are significantly lower, usually $<20 \%$ in plants (Fig. 5B). Although there is little sequence similarity between enzymes of different classes, there is significant conservation in overall structure (Fig. 6).

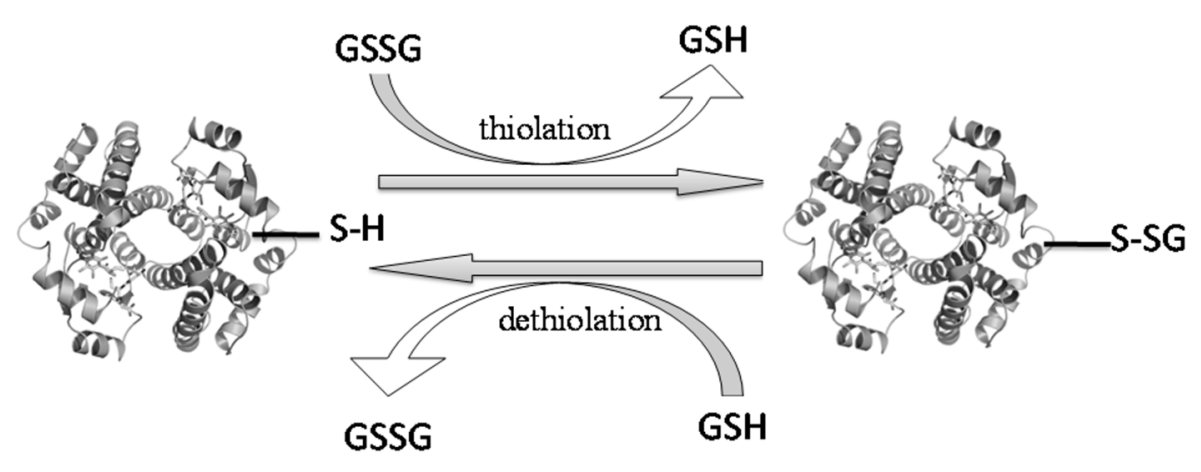

Fig. (3). Thioltransferase activity plays regulatory and protective role through reversible thiolation and dethiolation reactions. 


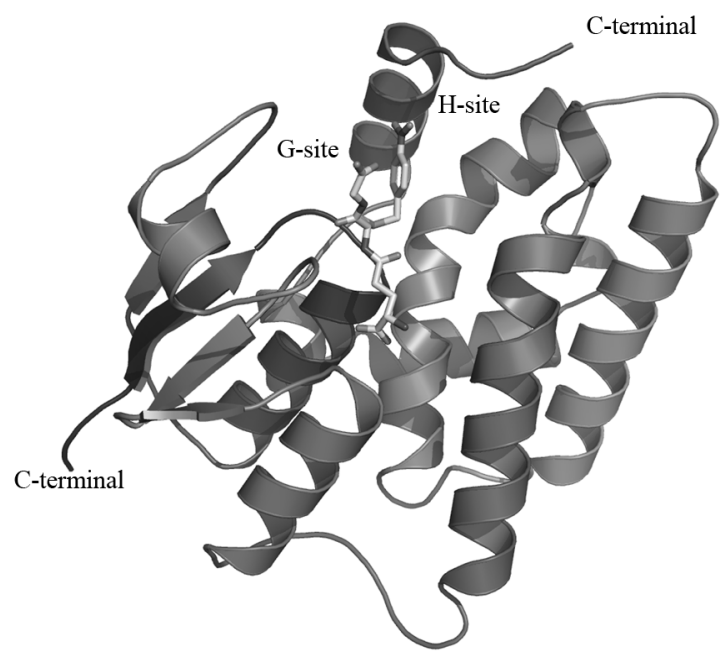

(A)

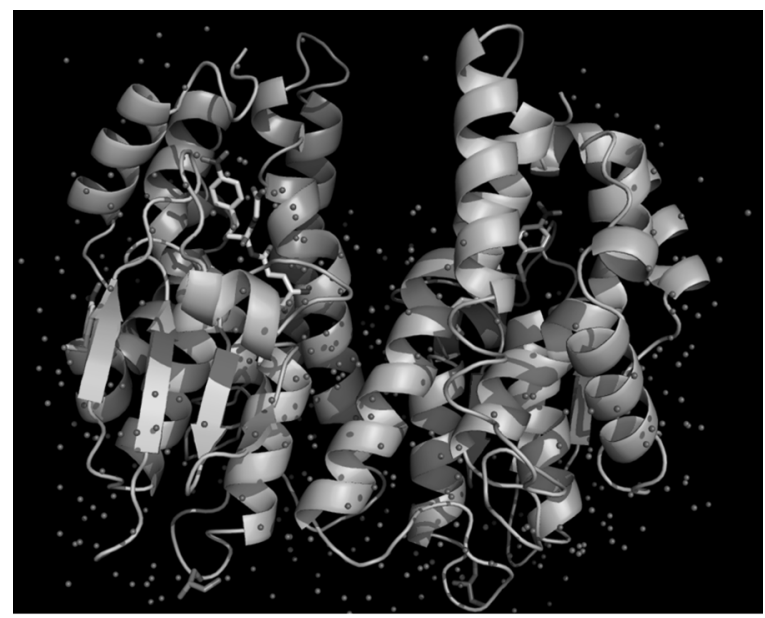

(B)

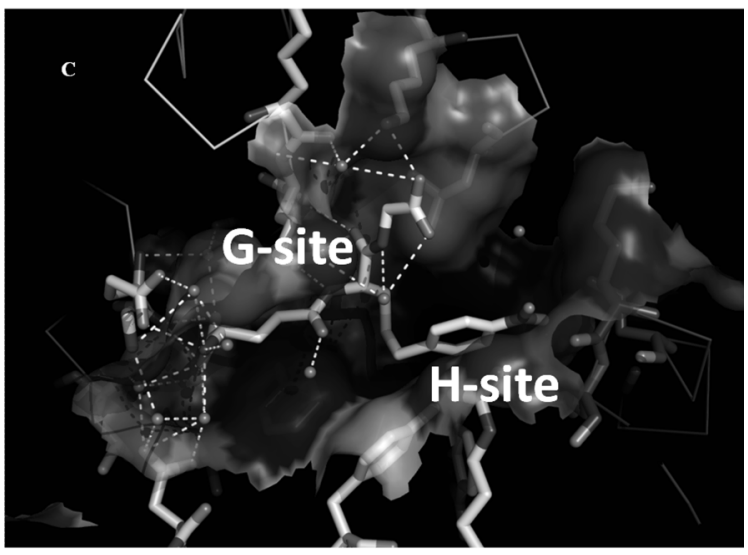

(C)

Fig. (4). A cartoon representation of the tau class GmGSTU4-4 monomer (A), dimer (B) and the substrate binding site $(\mathbf{C})$. Secondary structure elements and the location of G- and H-site are labelled. The water molecules are represented by spheres. The bound inhibitor S-(p-nitrobenzyl)-glutathione $(\mathrm{Nb}-\mathrm{GSH})$ is shown in a stick representation. The figures were produced using PyMol.
Each subunit adopts the same folding pattern, which is called 'GST fold', and consists of two distinct domains: a highly conserved N-terminal GSH binding domain and structurally diverse Cterminal hydrophobic domain [76]. The Nterminal domain (approximately one third of the protein sequence), consisting of $\beta$-strands and $\alpha$ helices as secondary structure elements, usually $\beta \alpha \beta \alpha \beta \beta \alpha$, similar to the thioredoxin fold $[78,79$, $86]$ and the all helical C-terminal domain composed of $\alpha$-helices arranged in a right-handed spiral (Fig. 4) [34, 87, 88]. Each subunit has an independent active site, consisting of two regions: a GSH binding site (G-site) in the N-terminal domain and a xenobiotic (hydrophobic) substrate binding site (H-site) in the C-terminal domain [30, 80, 81, 83, 84, 89] (Fig. 4A,C).

\subsection{Interactions between Subunits}

The interactions that are involved in assembling the quaternary structure of GSTs include salt bridges, hydrogen bonds, hydrophilic and hydrophobic interactions, including a lock-and-key motif that physically anchors the two subunits together [90-92]. The lock-and-key motif is a common feature of GSTs of the tau, phi, alpha, mu and pi classes [82, 90, 91]. Only subunits with the same interfacing type appear to be compatible for dimerization. Subunits from different classes of GST are not able to dimerize because of the incompatibility of the interfacial residues $[93,94]$.

\subsection{GSH Binding Site (G-site)}

In each monomer the G-site is located in a polar region, formed by the beginning of helices $\mathrm{H} 1, \mathrm{H} 2$, and $\mathrm{H} 3$ in the N-terminal domain, (Fig. 4A,C Fig. 7) [83]. The G-site contains specific residues critical for GSH binding and catalytic activity. In particular, a highly conserved, catalytically essential Ser of the tau (Ser13 in GmGSTU4-4) [83, 95], phi, zeta, and theta classes plant and of insect delta class GSTs and Tyr of the mammalian alpha, mu, pi classes GSTs have a crucial role in the mechanism of GSH activation [11]. The Ser/Tyr hydroxyl group acts as hydrogen bond donor to the thiol group of GSH, contributing to stabilization of reactive thiolate anion which is the nucleophile group for the electrophilic substrate $[87,96]$. GSTs that belong to the, omega, beta, lambda and DHAR classes contain instead of Ser/Tyr, a catalytically essential Cys, that changes enzyme properties, 
A

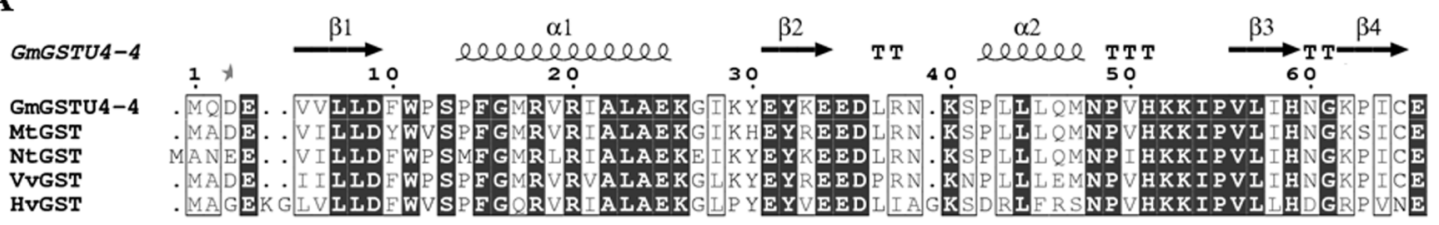

$\alpha 3$

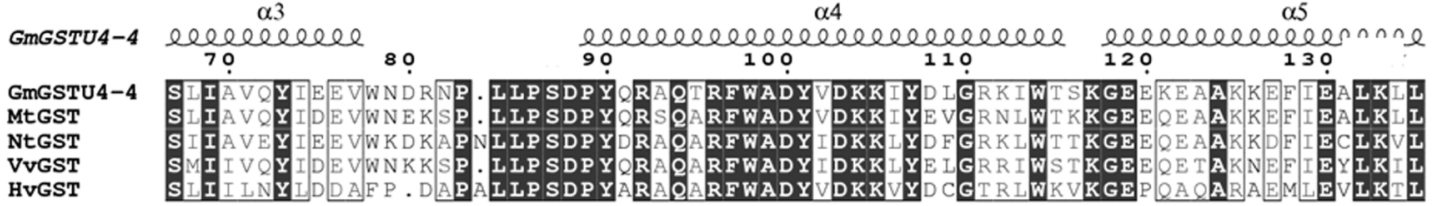

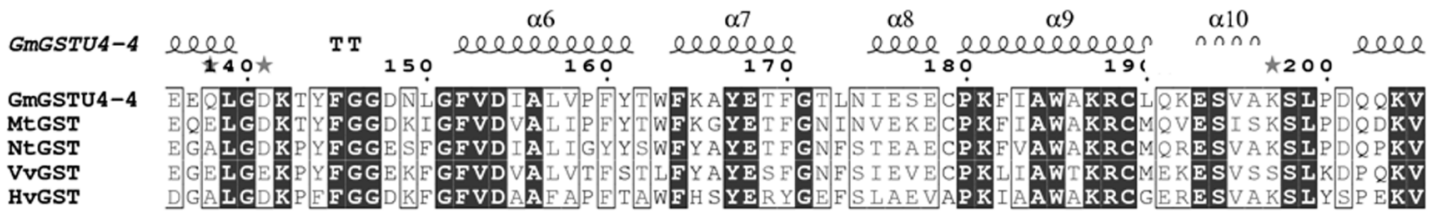

GmGSTU4-4 $\begin{aligned} & \text { al1 } \\ & \begin{array}{c}\text { ele } \\ 210\end{array}\end{aligned}$

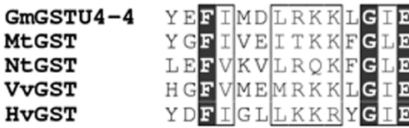

B AtGSTPhi

AtGSTTh

AtDHAR

AtGSTLambda

AtGSTTau

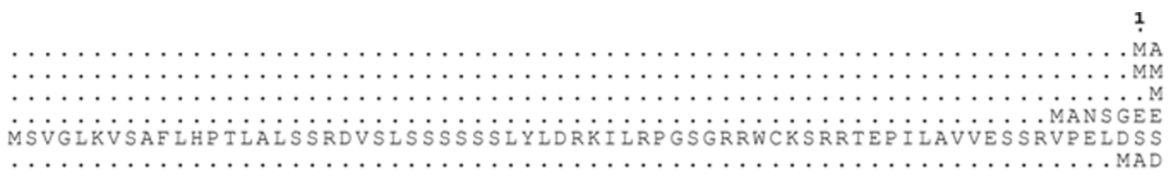

10

30

40

50

60

AtGSTPhi

AtGSTThet

AtDHAR

AtGSTZeta

AtGSTLambda
AtGSTTau

GIKVFGHPASTA

20

A. E......SRAVIIECKVNGIQFDEVIISIAKRQQLSPEFKDINPLGKVPAIVDGRL A I I CVKAAVGAPDHLGDCPESQRALITLEEKSITYKIHLINLSDKPQ...WFLDISPQGKVPVLKIDDK

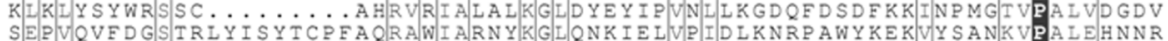

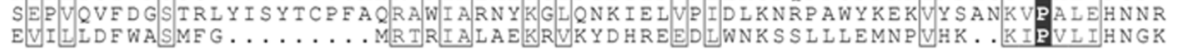

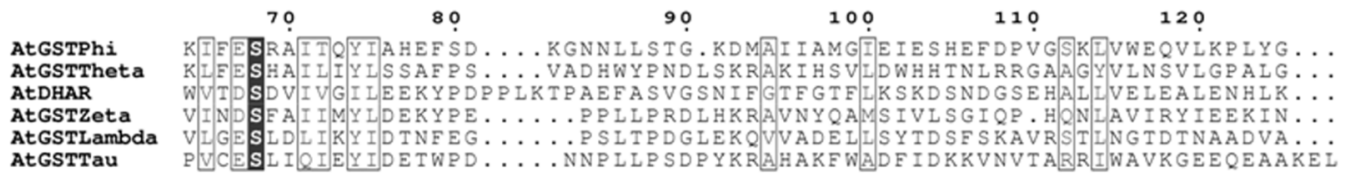

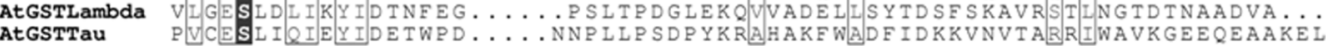

AtGSTPhi

AtGSTTheta

AtDHAR

AtGSTZeta

AtGSTzeta

AtGSTTau

$130 \quad 140 \quad 150$

160

170

180

MTTDKTVVEEEEAKLAKVLDVYEHR ..... LGESKYLAS. DHFTLVDIHTIPVIQYILGTPTK... RLFDE国 LPLNPKAA AEAEQLLTKSLSTLETFWL. KGNAKELLGSNQPSIADISLVCELMQIQVLDDKDRLRLLSI SHDGPFIAGERVSAVDLSLAPKLYHLQ. VALGHEKSWSVPESFPHVHNYMKTLFSIDSFER. TRTE

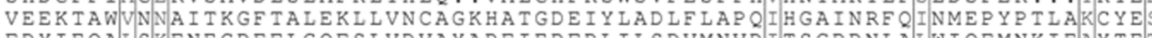

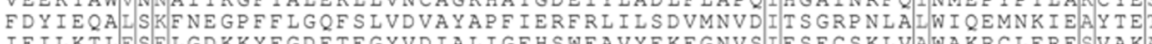

IEILKTLESELGDKKYFGDETEGYVDIALIGEHSWFAVYEKEGNVSIESECSKLVAWAKRCLERESVAK

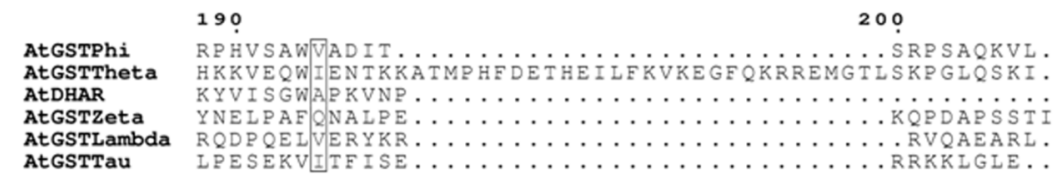

(Fig. 5) Contd.... 


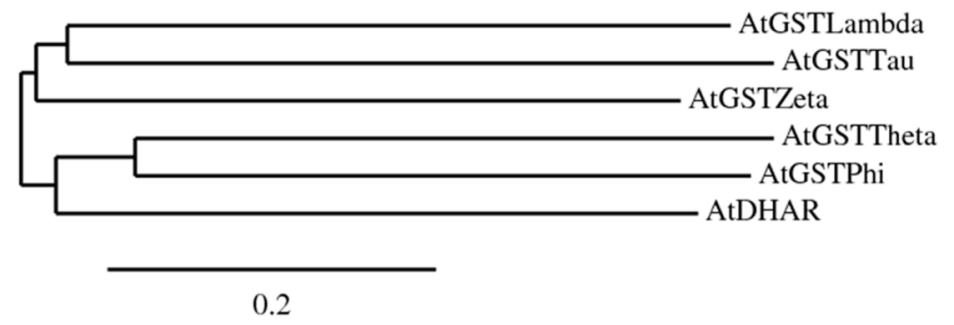

Fig. (5). A: Sequence alignment of members of the tau family of GSTs compared with the secondary structure of GmGSTU4-4 (PDB code 2VO4) produced using ESPript (http://espript.ibcp.fr/ESPript/ESPript/). GmGSTU4-4 numbering is shown above the alignment. Alpha helices and beta strands are represented as helices and arrows, respectively, and beta turns are marked with TT. Conserved areas are shown shaded. A column is framed, if more than $70 \%$ of its residues are similar according to physico-chemical properties. This sequence alignment was created using the following sequences (NCBI accession numbers are in parentheses): GmGSTU4-4: Glycine max (AAC18566), NtGST: Nicotiana tabacum (CAA39707), VvGST: Vitis vinifera (XP_002263395), MtGST: Medicago truncatula (ACJ85907), HvGST: Hordeum vulgare (ABI18247). B: Sequence alignment of representative members of the Arabidopsis thaliana GST family (phi, theta, DHAR, lambda and tau). Conserved areas are shown shaded. A column is framed, if more than $70 \%$ of its residues are similar according to physico-chemical properties. This sequence alignment was created using the following sequences (NCBI accession numbers are in parentheses): AtGST Phi (NP_171792); AtGST theta (NP_198937); AtDHAR (Q9FWR4); AtGST zeta (Q9ZVQ3); AtGST tau (AAS76278); AtGST lambda (NP_191064). C: Phylogenetic analysis of representative members of the Arabidopsis thaliana GST family (phi, theta, DHAR, lambda and tau) (TreeDyn program run at http://www.phylogeny.fr/).

which is involved in forming a mixed disulfide with GSH [14, 20, 97]. Cys residue is highly conserved in all plant DHARs' and is thought to be responsible for binding to DHA [98].

The analysis of crystal structures of soluble GSTs clearly demonstrates that, several active-site residues and a functionally conserved electronsharing network contributes to the formation and stabilization of the thiolate anion. Amino acids mainly with positive charges for instance Arg 18 ( $\alpha$-helix H1) located at the bottom of the G-site, which is conserved among all tau GST sequences, although not involved directly in the formation of the G-site, seems to have an indirect role in GSH binding, and in stabilization of G-site architecture through a network of hydrogen bonds and electrostatic interactions [83].

\subsection{Electrophilic Binding Site (H-site)}

Unlike the conserved N-terminal domain, the sequence of C-terminal domain is variable [83, 84]. The H-site is composed of non-conserved residues from the C-terminal domain (Fig. 4), showing diversity in substrate specificity (Fig. 5A) [99]. For example, the H-site of GmGSTU4-4 is typically hydrophobic, and is built predominantly by hydrophobic residues from the C-terminal domain: helix H4a, (Tyr107, Arg111), helix H6 (Trp163) helix H9 (Phe208, Leu212, Lys215 and Leu216), and Phe10 and Leu37 from the Nterminal domain $[83,84]$.

Regarding variability, the most variable regions include the C-terminal residues and the upper part of the two long helices in the C-terminal domain. Moreover, plant GSTs possess a larger $\mathrm{H}$-site for hydrophobic substrate binding, compared to mammalian GSTs, and therefore are able to accept a larger and much more diverse substrates [83, 84].

\subsection{Ligand Binding Site (L-site)}

In addition to their catalytic function GSTs act as ligand-binding proteins and bind hydrophobic molecules (azo-dyes, bilirubin, heme, polycyclic aromatic hydrocarbons, steroids, thyroid hormones, plant hormones and flavonoids) in a nonsubstrate manner into a distinct site. This site is termed L-site [12, 83, 100-105] and seems to play a role in storage and transport of these compounds in the cell [106].

Little information is available about the exact localization and the nature of the L-site in GSTs. 

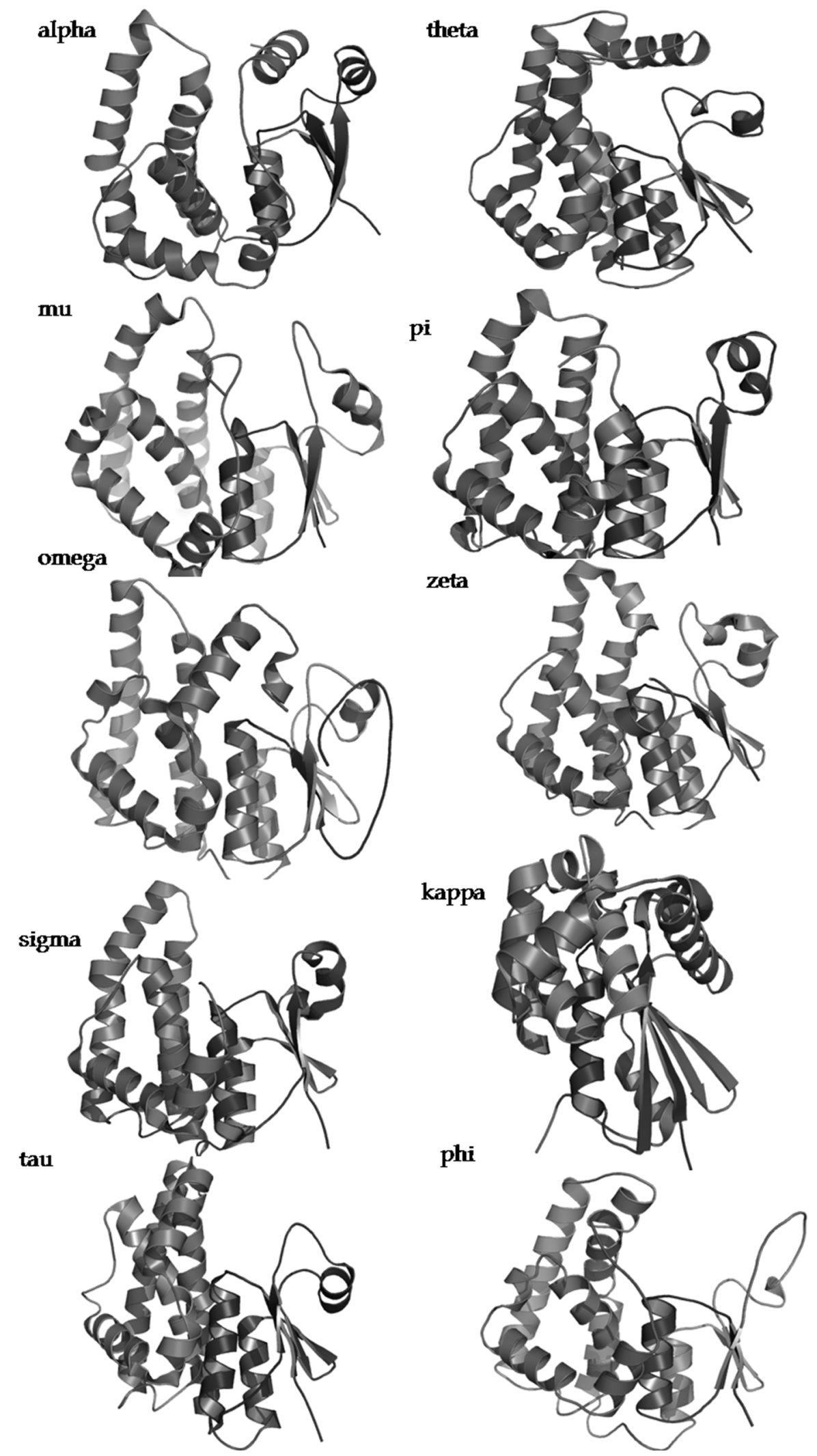

Fig. (6). Ribbon representations of the structures of the GST classes: alpha (PDB code: 1gse), mu (PDB code: 1hna), pi (PDB code: 1glp), theta (PDB code: $1 \mathrm{ljr}$ ), zeta (PDB code: $1 \mathrm{fw} 1)$, omega (PDB code: 1eem), sigma (PDB code: 1mou), kappa (PDB code: 1yzx), phi (PDB code: 1aw9), tau (PDB code: 1gwc). The figure was produced using PyMoL. 


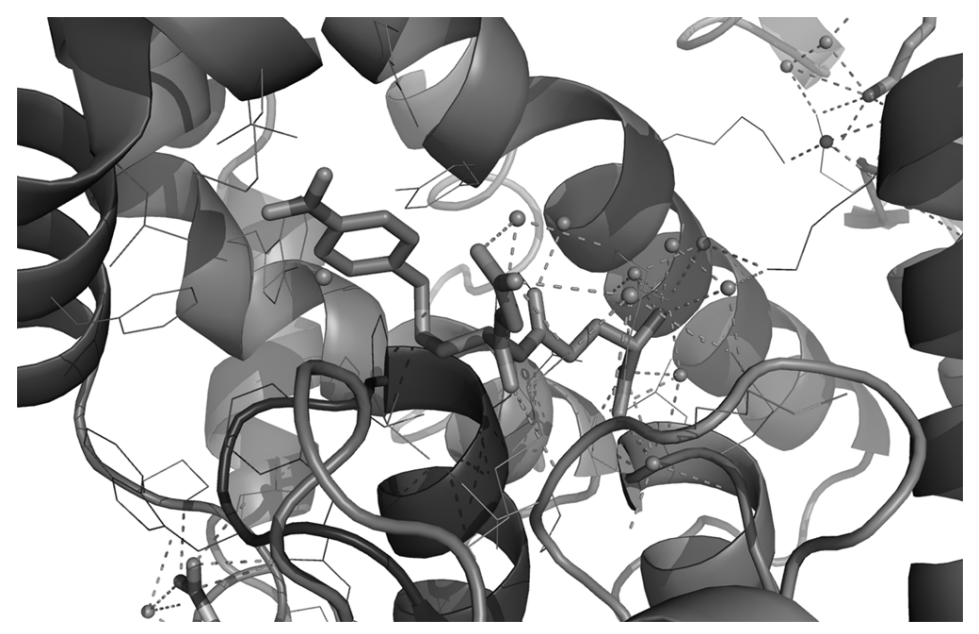

(A)

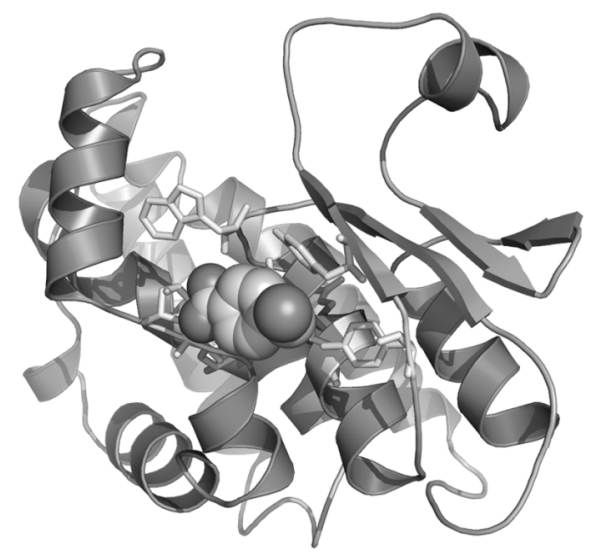

(B)

Fig. (7). A: Cartoon representation of the G- and H-site of GmGSTU4-4 with the inhibitor S-(p-nitrobenzyl)glutathione. Amino acid side chains that contribute directly to $G$ and $H$-site formation are shown in a stick representation. B: A representation of the putative L-site of GmGSTU4-4 with the ligand (4-nitrophenyl)-methanethiol. The ligand (4-nitrophenyl)-methanethiol is represented as a ball-and-stick. Amino acid side chains that contribute to Lsite formation are shown in a stick representation. The figure was produced using PyMol.

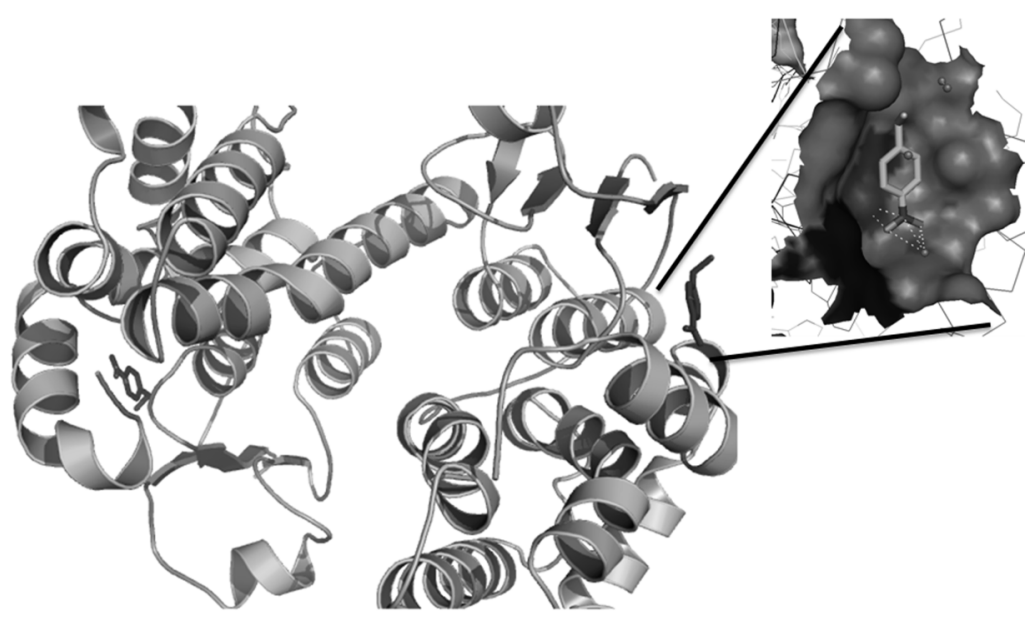

Fig. (8). A representation of the putative L-site of GmGSTU4-4 with the ligand (4-nitrophenyl)-methanethiol. The ligand (4-nitrophenyl)-methanethiol is represented as a stick. The figure was produced using PyMol. 
Variation in the location of L-site between different GST isoenzymes is a well-known feature of GSTs. For example, the L-site in GmGSTU4-4 was found to bind the molecule (4-nitrophenyl) methanethiol [83] and is located in a hydrophobic surface pocket formed by Trp11, Arg20, Tyr30, Tyr32, Leu199 and Pro200 (Fig. 7B, 8). The main binding residues (Trp11, Arg20, Tyr30 and Tyr32) are, in general, conserved within the tau GST family (Fig. 5A). On the other hand, the L-site of GST from Schistosoma japonica [100] is located at the dimer interface. In the case of the Arabidopsis enzyme [107], the L-site is located next to the G-site between the side chains of helices $\alpha 3^{\prime \prime} / \alpha 3^{\prime \prime}$ ', and $\alpha 5$ ', whereas the L-site of the human pi class GST and the maize GST I is located into the H-site [101, 104]. Dixon et al., (2011) [108] demonstrated that the Arabidopsis AtGSTF2 binds camalexin and flavonol quercetin-3-O-rhamnoside with high affinity (typically $\mathrm{K}_{\mathrm{d}}<1 \mu \mathrm{M}$ ). The binding is enhanced in the presence of GSH and by the other heterocyclic ligands. With GSTF2, these secondary ligand associations resulted in an allosteric enhancement in GSH-conjugating activity. The authors concluded that $A t \mathrm{GSTF} 2$ play important role in regulating the binding and transport of defence-related compounds in planta.

The precise role of L-site is unclear. However, it has been proposed that binding of non-substrate ligands to GST prevents modification (e.g. degradation, oxidation) of the molecules in vivo. Another possibility is that GST prevents cellular damage that may be caused by cytotoxic and genotoxic compounds. The other possibility is that binding to L-site may help to the delivery of the ligands to specific cellular protein receptors or compartments [83, 101, 102, 104]. Lu and Atkins (2004) have demonstrated the possible antioxidant role for the ligandin activity of GSTs [40]. More recently, Dixon and Edwards have shown that GSTUs from Arabidopsis thaliana are able to bind tightly thioester of fatty acids with varied chain length $\left(\mathrm{C}_{(6)}\right.$ to $\left.\mathrm{C}_{(18)}\right)$, oxygen content, and desaturation, with $\mathrm{K}_{(\mathrm{d})}$ approximately $1 \mu \mathrm{M}$ [109]. The strong binding of various fatty acids by GSTUs and the conservation in binding observed in the different hosts suggest that GSTUs have selective roles in binding and conjugating these unstable metabolites in vivo. In addition, the same group of researchers has demonstrated the ability of GSTs to act as ligand binding proteins of porphyrins in vitro [110]. This ability results in highly specific interactions with porphyrinogen intermediates, which can be demonstrated in both plants and bacteria in vivo [111].

\section{ROLE OF GSTS IN ABIOTIC STRESS TOLERANCE}

Significant progress has been achieved in the previous years regarding the ability of GSTs to confer resistance to abiotic stresses like herbicides, drought salinity and heavy metals.

Plants in order to overcome stresses have evolved sophisticated and coordinated defense responses [112, 113] against endogenous and exogenous cytotoxic compounds, such as xenobiotics, including herbicides. These systems incorporate a three phase detoxification mechanism [112-116]. GSTs are phase II detoxyfing enzymes, catalyzing the conjugation of the xenobiotic with GSH.

Salinity, drought and temperature stresses, are the primary causes of crop loss worldwide. These abiotic stresses affect plant metabolism and cause important changes in growth, development and gene expression of plants [117]. The recent advances on GSTs have increased our understanding of their role mediated stress tolerance.

Glycin max L. under salt stress $(200 \mathrm{mM} \mathrm{NaCl})$ showed significant increase in GST activity, but when plants were sprayed with, sodium nitroprusside (SNP), a widely used NO donor, presented lower activity in soybean leaves at $0 \mathrm{~h}$ and $12 \mathrm{~h}$, while it increased at $6 \mathrm{~h}$, supported by GST isoenzyme activities. This action could be attributed to the exogenous NO application which induced GST activity in an ABA-dependent manner. Moreover, G. max plants showed increase, GST1 and GST4 transcript levels in both salt-stressed and SNP pretreated and subsequently stressed samples at $6 \mathrm{~h}$ and $12 \mathrm{~h}$, while a more variable regulation pattern was observed in plants treated only with SNP [118].

Solanum lycopersicum salt treatment resulted in the overexpression of selected GSTs (SIGSTU23, SlGSTU26) in the leaves while other like GSTs from lambda, theta, dehydroascorbate reductase and from the zeta classes (SlGSTL3, SlGSTT2, SlDHAR5, SlGSTZ2) in the roots [119]. 
It is interesting that a GST from Tamarix hispida found to be downregulated by drought and salinity stress [120]. Transgenic Arabidopis plants overexpressing this GST showed enhanced tolerance to drought and salinity stress while found to have increased levels of GST, GSH peroxidase, superoxide dismutase and peroxidase activity, along with decreased malondialdehyde content, electrolyte leakage rates and reactive oxygen species (ROS) levels under salt and drought stress conditions [120]. These results suggest that the enzyme per se has the ability to confer tolerance to abiotic stress caused by drought and salinity but in Tamarix hispida there must be an alternative mechanism operating regulating the expression of GSTs [120]. In barley, five GST genes were investigated all were up-regulated significantly under drought stress and/or showed a higher level of transcripts in the tolerant cultivar. In addition, it showed increased GST enzyme activity while it did not changed in the sensitive genotype under drought conditions. The sensitive genotype showed also higher levels of lipid peroxidation, suggesting that GSTs might be an important factor in the drought tolerance of barley genotypes [121].

Another role of GSTs is their involvement in tolerance to heavy metals. This role of GSTs could also be used for the detoxification of polluted soils contaminated by the extensive use of hexavalent chromium $[\mathrm{Cr}(\mathrm{VI})]$ in the industry. Tripathi et al. reported that yeast cells overexpressing two rice (Oryza sativa) GSTs OsGSTU30 and OsGSTU41 had normal growth, but had much higher levels of GST activities and showed enhanced resistance to $\mathrm{Cr}(\mathrm{VI})$ as compared to control cells. Moreover, yeast cells showed increased accumulation of chromium compared to the control cells [122].

GSTs have also been found to be able to detoxify the explosive 2,4,6-trinitrotoluene (TNT) is a major worldwide military pollutant. More specifically two GSTs, GST-U24 and GST-U25, from Arabidopsis thaliana have been found to be upregulated when exposed to TNT and to react with it forming three TNT glutathionyl products [123].

Although we have gained a better understanding on the resistance the GSTs and how they confer tolerance to plants against various stresses [124-126], very little is known on the regulatory mechanism and promoter analysis of specific GST genes. Yet, it has been found that certain GSTs, are induced by a wide range of xenobiotics or other biotic/abiotic stresses, suggesting that there is a specific mechanism. So far the analysis of the GST promoters failed to identify elements related to biotic or abiotic stresses like those found in in animal GST promoters [32]. However, an ocs element which is an plant enhancer sequence has been characterized in some of the GST promoters [128]. Ocs elements have been found to be induced by auxin or auxin analogs, the plant defense signal, and salicylic acid [129]. In addition, other elements like auxin-responsive elements [130] and ethylene-responsive elements [131] have been identified in GST promoters that might be responsible for auxin- and ethylene-induced GST expression, respectively.

Csiszar et al [132] have found significant changes in the expression of specific GSTs when Solanum lycopersicum was treated by salycilic acid at doses as low as $10^{-4} \mathrm{M}$. The differential expression of GSTs might be a mechanism of maintaining redox homeostasis during adverse conditions [132].

However, the molecular mechanisms regulating plant GST expression have yet to be identified. The completion of genome sequence from many different plants is expected to facilitate the identification of the cis-acting regulatory elements [133, 134]. Furthermore the trans-acting DNA binding factors are also expected to be identified thus allowing plant GST transcriptional regulation to be clarified.

\section{ROLE OF GSTS IN BIOTIC STRESS TOL- ERANCE}

Pathogen infection elicits the expression of disease related genes resulting in the production of several toxic plant products as well as reactive oxygen species [135]. In a number of studies, it has been reported the biological relevance of GSTs to pathogen attack. However, little is known about their regulatory or catalytic role during pathogen infection. In general it has been proposed that GSTs play a role in the reduction of damage caused by pathogens or diminishing the extent of cell death caused by the hypersensitive response (HR) [136].

A GST gene ( $P v$ GST3-3) from $P$. vulgaris is induced after the infection with the fungus Uromyces appendiculatus. A number of findings further 
support that $P v$ GSTU3-3 plays a crucial role under biotic stress conditions. Expression of $P v$ GSTU3-3 in $E$. coli revealed that it exhibits hydroperoxidase, thioltransferase, and dehydroascorbate reductase catalytic function. In addition, due to its low $K_{\mathrm{m}}$ for GSH relative to other plant GSTs, is possibly able for efficient catalysis under low reduced GSH concentration (e.g., oxidative stress). Finally, a regulatory role in the release of isothiocyanates has been proposed due to its ability to conjugate GSH with isothiocyanates [124].

Global transcriptome analysis of poplar plants infected by $B$. dothidea revealed that GSTs transcripts were accumulated to high levels. Ten of the most highly expressed transcripts had high sequence homology to GSTs from other plant species. Based on present annotation, in addition to transferase activity these GSTs implicated in defense responses and auxin-mediated signaling pathways, involved in aromatic amino acid metabolism, induced by $\mathrm{H}_{2} \mathrm{O}_{2}$ and by the pathogens Botrytis cinerea or Pseudomonas syringae. According to these results, it seems that GSTs are closely associated with responses to $B$. dothidea in infected poplar plants and, each member of GST subfamilies performed a slightly different functional role to defend against these pathogen [137].

Four tau GST genes (NbGSTU1, NbGSTU2 and $N b G S T U 3$ ) and one phi GST (NbGSTF1) from $N$. benthamiana plants were examined for their roles in fungal infection. Expression levels of $N b$ GSTU1 and $N b G S T U 3$ increased remarkably post infection while those of $\mathrm{NbGSTU} 2$ and $N b G S T F 1$ were not changed. Furthermore, it was examined the performance of inoculated $N$. benthamiana plants following gene silencing. A significant increase in susceptibility was recorded only for $\mathrm{NbGSTU1-knockdown}$ plants. These findings suggest that distinct GST genes involved in disease development and that the responsiveness to fungal infection differs between the GST genes [136].

A negative role of GST genes has also been proposed in plant responses against pathogen infection. N. tabacum plants infected with $P$. parasitica var. nicotianae showed a major increase in a specific GST gene. In order to verify its involvement in the host response to fungal infection, GST silenced plants was developed. A significant increase in resistance was recorded in GST silenced plants. Possibly, the combined action of several gene products are under the direct or indirect control of this GST gene which appears to act as a negative regulator in the defense response of tobacco to $P$. parasitica [138].

A tau GST gene for $N$. benthamiana NbGSTU4 with $80 \%$ identity to $N b G S T U 2$ [136] upregulated in $N$. benthamiana post Bamboo mosaic virus (BaMV) infection. With the view to functionally characterize the role of NbGSTU4 in BaMV infection, the NbGSTU4 was knocked down or was transiently expressed in $N$. benthamiana. When the expression level of NbGSTU4 is reduced, a significant decrease in BaMV RNA accumulation was recorded. In contrast, the accumulation of viral RNA increases when NbGSTU4 is transiently expressed. The results suggest that NbGSTU4 involved in the infection cycle of BaMV. The NbGSTU4 enables the unhindered synthesis of minus-strand RNA by providing either an antioxidative moiety or by changing the redox state of replicase complex [139].

A growing body of evidence suggests that GST enzymes play a role in plants disease susceptibility. However, no clear picture has manifested yet. A number of important questions remain to be addressed. Which are the exact roles of GSTs in infected plants? Is there specific GSTs that respond to different pathogens? What is the molecular mechanism that governs plant GST expression under biotic stress conditions? Further research is needed to answer the above questions.

In conclusion, the plant GST family of enzymes belongs to the thioredoxin superfamily classified by the common GSH binding domain-adopted thioredoxin fold. The GST family represents a group of catalysts with multiple roles many of which are important in counteracting biotic and abiotic stress. These roles can be relevant to maintaining cellular homeostasis as well as in the direct detoxification of toxic compounds. The detoxification roles of GSTs arise for their ability to catalyze the conjugation of GSH to a large number of electrophilic molecules. The antioxidant catalytic function of GSTs is exhibited through peroxidase, thioltransferase and dehydroascorbate reductase activity. Further analysis and study of this protein family will inevitable reveal many examples of functional and catalytic diversification and will highlight the importance of these enzymes in the 
protection against the oxidative stress and in other cellular processes.

\section{LIST OF ABBREVIATIONS}

CDNB $=$ 1-chloro-2,4-dinitrobenzene
GSH $=$ Glutathione
GST $=$ Glutathione transferase
G-site $=$ GSH binding site
GPx $=$ Glutathione peroxidase
H-site $=$ Hydrophobic binding site
Nb-GSH $=$ S-(p-nitrobenzyl)-glutathione
ROS $=$ Reactive Oxygen Species.

\section{CONFLICT OF INTEREST}

The author(s) confirm that this article content has no conflict of interest.

\section{ACKNOWLEDGEMENTS}

EC, KK, GV, EB, INO, PM, NEL acknowledge financial support from the grant program THALES (grant number 380236), co-funded by the European Union-European Social Fund and National Resources. The grant THALES-“Glutathione transferases: multifunctional molecular tools in red and green biotechnology" falls under the Operational Programme "Education and Lifelong Learning".

\section{DISCLOSURE}

This article is an updated version of the article published in Current Chemical Biology 12/2010; 5(1):64-74. DOI: 10.2174/187231311793564306.

\section{REFERENCES}

[1] Marrs KA. The functions and regulation of glutathione S-transferases in plants. Annu Rev Plant Physiol Plant Mol Biol 1996; 47: 127-58.

[2] McGonigle B, Keeler SJ, Lau SM, Koeppe MK, O'Keefe DP. A genomics approach to the comprehensive analysis of the glutathione S-transferase gene family in soybean and maize. Plant Physiol 2000; 124: 1105-20.

[3] Edwards R, Dixon DP. Plant glutathione transferases. Methods Enzymol 2005; 401: 169-86.

[4] Chronopoulou EG, Labrou NE. Glutathione transferases: emerging multidisciplinary tools in red and green biotechnology. Recent Pat Biotechnol 2009; 3: 211-23.

[5] Kranner I, Birtic S, Anderson KM, Pritchard HW. Glutathione half-cell reduction potential: A universal stress marker and modulator of programmed cell death. Free Rad Biol Med 2006; 40: 2155-65.

[6] Gutscher M, Pauleau AL, Marty L, et al. Real-time imaging of the intracellular glutathione redox potential. Nat Methods 2008; 5: 553-59.

[7] Pallardo FV, Markovic J, Garcia JL, Vina J. Role of nuclear glutathione as a key regulator of cell proliferation. Mol Aspects Med 2009; 30: 77-85.

[8] Rouhier N, Lemaire SD, Jacquot JP. The role of glutathione in photosynthetic organisms:emerging functions for glutaredoxins and glutathionylation. Annu Rev Plant Biol 2008; 59: 143-66.

[9] Zechmann B, Müller M. Subcellular compartmentation of glutathione in dicotyledonous plants. Protoplasma 2010; 246: 15-24.

[10] Dixon DP, Skipsey M, Edwards R. Roles for glutathione transferases in plant secondary metabolism. Phytochemistry 2010; 71: 338-50.

[11] Sheehan D, Meade G, Foley VM, Dowd CA. Structure, function and evolution of glutathione transferases: implications for classification of nonmammalian members of an ancient enzyme superfamily. Biochem J 2001; 360: 1-16.

[12] Droog F. Plant Glutathione S-Transferases, a Tale of Theta and Tau. J Plant Growth Regul 1997; 16: 95-107.

[13] Edwards R. Characterisation of glutathione transferases and glutathione peroxidases in pea (Pisum sativum). Physiol Plant 1996; 98: 594-604.

[14] Dixon DP, Davies BG, Edwards R. Functional divergence in the glutathione transferase superfamily in plants: identification of two classes with putative functions in redox homeostasis in Arabidopsis thaliana. J Biol Chem 2002; 277: 30859-69.

[15] Dixon DP, Lapthorn A. Edwards R. Protein family review: Plant glutathione transferases. Genome Biol 2002; 3: 3004.1-10.

[16] Liu YJ, Han XM, Ren LL, Yang HL, Zeng QY. Functional Divergence of the Glutathione S-Transferase Supergene Family in Physcomitrella patens Reveals Complex Patterns of Large Gene Family Evolution in Land Plants. Plant Physiol 2013; 161: 773-86.

[17] Lan T, Yang ZL, Yang X, Liu YJ, Wang XR, Zenga QY. Extensive Functional Diversification of the Populus Glutathione S-Transferase Supergene Family. Plant Cell 2009; 21: 3749-66.

[18] Dixon DP, Edwards, R. Roles for stress-inducible lambda glutathione transferases in flavonoid metabolism in plants as identified by ligand fishing. J Biol Chem 2010; 285: 36322-29.

[19] Jain M, Ghanashyam C, Bhattacharjee A. Comprehensive expression analysis suggests overlapping and specific roles of rice glutathione S-transferase genes during development and stress responses. BMC Genomics 2010; 11: 73-89.

[20] Lallement P, Brouwer B, Keech O, Hecker A, Rouhier $\mathrm{N}$. The still mysterious roles of cysteinecontaining glutathione transferases in plants. Front Pharmacol 2014; 5: 1-22.

[21] Runarsdottir A, Mannervik B. A novel quasi-species of glutathione transferase with high activity towards naturally occurring isothiocyanates evolves from 
promiscuous low-activity variants. J Mol Biol 2010; 401: 451-64.

[22] Balogh LM, Le Trong I, Kripps KA, Shireman LM, Stenkamp RE, Zhang W, Mannervik B, Atkins WM. Substrate specificity combined with stereopromiscuity in glutathione transferase A4-4-dependent metabolism of 4-hydroxynonenal. Biochemistry. 2010; 49: 1541-8.

[23] Kurtovic S, Mannervik B. Identification of emerging quasi-species in directed enzyme evolution. Biochemistry 2009; 48: 9330-9.

[24] Skopelitou K, Platis D, Axarli I, Labrou, NE. Glutathione transferases in drug discovery and development: towards safer and efficacious drugs. In: Attaur-Rahman, Caldwell GW, Choudhary MI, Yan Z, Eds. Frontiers in Drug, Design and Discovery. Bentham Science Publishers, 2009: Pp. 23-42.

[25] Oakley A. Glutathione transferases: a structural perspective. Drug Metab Rev 2011; 43: 138-51.

[26] Hou L, Honaker MT, Shireman LM, et al. Functional promiscuity correlates with conformational heterogeneity in A-class glutathione S-transferases. Biol Chem 2007; 282: 23264-74.

[27] Lo Piero AR, Puglisi I, Petrone G. Gene isolation, analysis of expression, and in vitro synthesis of glutathione S-transferase from orange fruit [Citrus sinensis L. (Osbeck)]. J Agric Food Chem 2006; 54: 9227-33.

[28] Cummins I, Cole DJ, Edwards R. Purification of multiple glutathione transferases involved in herbicide detoxification from wheat (Triticum aestivum L.) treated with the safener fenchlorazole-ethyl. Pestic Biochem Physiol 1997; 59: 35-49.

[29] Kampranis SC, Damianova R, Atallah M, et al. A novel plant glutathione S-transferase/peroxidase suppresses bax lethality in yeast. J Biol Chem 2000; 275: 29207-16.

[30] Thom R, Cummins I, Dixon DP, Edwards R, Cole DJ, Lapthorn AJ. Structure of a tau class glutathione Stransferase from wheat active in herbicide detoxification. Biochemistry 2002; 41: 7008-20.

[31] Cho HY, Kong KH. Study on the biochemical characterization of herbicide detoxification enzyme, glutathione S-transferase. Biofactors 2007; 30: 281-87.

[32] Frova C. The plant glutathione transferase gene family: genomic structure, functions, expression and evolution. Physiol Plant 2003; 119: 469-79.

[33] Mannervik B. Glutathione peroxidase. Methods Enzymol 1985; 113: 490-95.

[34] Mannervik B, Danielson UH. Glutathione transferases-structure and catalytic activity. CRC Crit Rev Biochem 1988; 23: 283-337.

[35] Cummins I, Cole DJ, Edwards R. A role for glutathione transferases functioning as glutathione peroxidases in resistance to multiple herbicides in blackgrass. Plant J 1999; 18: 285-92.

[36] Dixon DP, Cummins I, Cole DJ, Edwards R. Glutathione mediated detoxification systems in plants. Curr Opin Plant Biol 1998; 1: 258-66.

[37] Puglisi I, Lo Cicero L, Lo Piero AR. The glutathione S-transferase gene family: an in silico approach to study the post translational regulation. Biodegradation 2013; 24: 471-85.

[38] Huberts DH, van der Klei IJ. Moonlighting proteins: an intriguing mode of multitasking. Biochim Biophys Acta. 2010; 1803: 520-25.

[39] Jeffery CJ. Moonlighting proteins- an update. Mol Biosyst 2009; 5: 345-50.

[40] Lu WD, Atkins WA. Novel Antioxidant Role for Ligandin Behavior of glutathione S-Transferases: Attenuation of the Photodynamic Effects of Hypericin. Biochemistry 2004; 43: 12761-69.

[41] Ginsberg G, Smolenski S, Hattis D, Guyton KZ, Johns DO, Sonawane B. Genetic Polymorphism in Glutathione Transferases (GST): Population distribution of GSTM1, T1, and P1 conjugating activity. J Toxicol Environ Health B Crit Rev 2009;12: 389-439.

[42] Allocati N, Federici L, Masulli M, Di Ilio C. Glutathione transferases in bacteria. FEBS J 2009; 276: 58-75.

[43] Wu Y, Fan Y, Xue B, et al. Human glutathione Stransferase P1-1 interacts with TRAF2 and regulates TRAF2-ASK1 signals. Oncogene 2006; 25: 5787-800.

[44] Laborde E. Glutathione transferases as mediators of signaling pathways involved in cell proliferation and cell death. Cell Death Differ 2010; 17:1373-80.

[45] Gancedo C, Flores CL. Moonlighting Proteins in Yeasts. Microbiol Mol Biol Rev 2008; 72: 197-210.

[46] Lian HY, Jiang Y, Zhang H, Jones GW, Perrett S. The yeast prion protein Ure2: structure, function and folding. Biochim Biophys Acta 2006; 1764: 535-45.

[47] Grill E, Winnacker EL, Zenk MH. Phytochelatins: the principle of heavy-metal complexing peptides of higher plants. Science 1985; 230: 674-76.

[48] Freeman JL, Persans MW, Nieman K, et al. Increased glutathione biosynthesis plays a role in nickel tolerance in Thlaspi nickel hyperaccumulators. Plant Cell 2004; 16: 2176-91.

[49] Noctor G, Veljovic-Jovanovic S, Foyer CH. Peroxide processing in photosynthesis: antioxidant coupling and redox signaling. Proc R Soc Lond B Biol Sci 2000; 355: 1465-75.

[50] Tausz M, Sircelj H, Grill D. The glutathione system as a stress marker in plant ecophysiology: is a stressresponse concept valid?. J Exp Bot 2004; 55: 1855-62.

[51] Rouhier N, Jacquot JP. The plant multigenic family of thiol peroxidases. Free Radic Biol Med 2005; 38: $1413-21$.

[52] Foyer $\mathrm{CH}$, Noctor G. Oxidant and antioxidant signaling in plants: a re-evaluation of the concept of oxidative stress in a physiological context. Plant Cell Environ 2005 ; 28 : 1056-71.

[53] Foyer CH, Halliwell B. The presence of glutathione and glutathione reductase in chloroplasts: a proposed role in ascorbic acid metabolism. Planta 1976; 133: 21-5.

[54] Noctor G, Foyer CH. Simultaneous measurement of foliar glutathione, $\gamma$-glutamylcysteine and amino acids by high-performance liquid chromatography: comparison with two other assay methods for glutathione. Anal Biochem 1998; 264: 98-110.

[55] Desikan R, Hancock J, Neill S. Reactive Oxygen Species as Signalling Molecules. In: Smirnoff N, Eds. 
Antioxidants and reactive oxygen species in plants. Blackwell Publishing Ltd. 2005: Pp. 169-196.

[56] Bartling D, Radzio R, Steiner U, Weiler EW. A glutathione S-transferase with glutathione-peroxidase activity from Arabidopsis thaliana. Molecular cloning and functional characterization. Eur J Biochem 1993; 216: 579-86.

[57] Moons A. Regulatory and functional interactions of plant growth regulators ant plant Glutathione Stransferases (GSTs). Vitam Horm 2005; 72: 155-202.

[58] Filomeni G, Rotilio G, Ciriolo MR. Glutathione disulfide induces apoptosis in U937 cells by a redoxmediated p38 MAP kinase pathway. FASEB J 2003; 17: 64-6.

[59] Circu ML, Aw TY. Glutathione and apoptosis. Free Radic Res 2008; 42: 689-706.

[60] Schafer FQ, Buettner GR. Redox environment of the cell as viewed through the redox state of the glutathione disulfide/glutathione couple. Free Radic Biol Med 2001; 30: 1191-1212.

[61] Sabeh F, Wright T, Norton SJ. Purification and characterization of a glutathione peroxidase from the Aloe vera plant. Enzyme Protein 1993; 47: 92-8.

[62] Eshdat Y, Holland D, Faltin Z, Ben-Hayyim G. Plant glutathione peroxidases. Physiol Plant 1997; 100: 234-40.

[63] Milla MAR, Maurer A, Huete AR, Gustafson JP. Glutathione peroxidase genes in Arabidopsis are ubiquitous and regulated by abiotic stresses through diverse signalling pathways. Plant J 2003; 36: 602-15.

[64] Navrot N, Collin V, Gualberto J, et al. Plant glutathione peroxidases are functional peroxiredoxins distributed in several subcellular compartments and regulated during biotic and abiotic stresses. Plant Physiol 2006; 142: 1364-79.

[65] Edwards R, Dixon DP. Plant glutathione transferases. Methods Enzymol 2005; 401: 169-86.

[66] Skipsey M, Andrews CJ, Townson JK, Jepson I, Edwards R. Substrate and thiol specificity of a stressinducible glutathione transferase from soybean. FEBS Lett 1997; 409: 370-74.

[67] Wagner U, Edwards R, Dixon DP, Mauch F. Probing the Diversity of the Arabidopsis glutathione STransferase Gene Family. Plant Mol Biol 2002; 49: 515-32.

[68] Wang W, Ballatori N. Endogenous Glutathione Conjugates: Occurrence and Biological Functions. Pharmacol Rev 1998; 50: 335-56.

[69] Mieyal JJ, Gallogly MM, Qanungo S, Sabens EA, Shelton MD. Molecular mechanisms and clinical implications of reversible protein S-glutathionylation. Antioxid Redox Signal 2008; 10: 1941-88.

[70] Dafre AL, Sies H, Akerboom T. Protein S-thiolation and regulation of microsomal glutathione transferase activity by the glutathione redox couple. Arch Biochem Biophys 1996; 332: 288-94.

[71] Lou MF. Redox regulation in the lens. Prog Retin Eye Res 2003; 22: 657-82.

[72] Hurd TR, Costa NJ, Dahm CC, et al. Glutathionylation of mitochondrial proteins. Antioxid Redox Signal 2005; 7: 999-1010.
[73] Benekos K, Kissoudis C, Nianiou-Obeidat I, et al. Overexpression of a specific soybean GmGSTU4 isoenzyme improves diphenyl ether and chloroacetanilide herbicide tolerance of transgenic tobacco plants. J Biotechnol 2010; 150:195-201.

[74] $\mathrm{Hu} \mathrm{T}$. A glutathione s-transferase confers herbicide tolerance in rice. Crop Breed Appl Biotechnol 2014; 14:76-81.

[75] Sharma R, Sahoo A, Devendran R, Jain M. Overexpression of a rice tau class glutathione S-transferase gene improves tolerance to salinity and oxidative stresses in Arabidopsis. PLoS ONE [serial online]2014; 9: e92900. Available at: http://journals.plos.org/ plosone/article?id=10.1371/journal.pone.0092900 [accessed 24 March 2014].

[76] Cummins I, Dixon DP, Freitag-Pohl S, Skipsey M, Edwards R. Multiple roles for plant glutathione transferases in xenobiotic detoxification. Drug Metab Rev 2011; 43: 266-80.

[77] Labrou NE, Mello LV, Clonis YD. Functional and structural roles of the glutathione-binding residues in maize (Zea mays) glutathione S-transferase I. Biochem J 2001; 358: 101-10.

[78] Martin JL. Thioredoxin-a fold for all reasons, Structure $1995 ; 3: 245-50$.

[79] Wilce MC, Parker MW. Structure and function of glutathione $\mathrm{S}$ transferases. Biochim Biophys Acta 1994; 1205: 1-18.

[80] Neuefeind T, Huber R, Dasenbrock H, Prade L, Bieseler B. Crystal structure of herbicide-detoxifying maize glutathione S-transferase-I in complex with lactoylglutathione: evidence for an induced-fit mechanism. J Mol Biol 1997; 274: 446-53.

[81] Neuefeind T, Huber R, Reinemer P, et al. Cloning, sequencing, crystallization and X-ray structure of glutathione S-transferase-III from Zea mays var. mutin: a leading enzyme in detoxification of maize. J Mol Biol 1997; 274: 577-87.

[82] Thom R, Dixon DP, Edwards R, Cole DJ, Lapthorn AJ. The structure of a zeta class glutathione Stransferase from Arabidopsis thaliana: characterisation of a GST with novel active-site architecture and a putative role in tyrosine catabolism. J Mol Biol 2001; 308: 949-62.

[83] Axarli, I, Dhavala, P, Papageorgiou, AC, Labrou, NE. Crystallographic and Functional Characterization of the Fluorodifen-inducible Glutathione Transferase from Glycine max Reveals an Active Site Topography Suited for Diphenylether Herbicides and a Novel Lsite. J Mol Biol 2009; 385: 984-1002.

[84] Axarli I, Dhavala P., Papageorgiou A.C., Labrou N.E. Crystal structure of Glycine max glutathione transferase in complex with glutathione: investigation of the mechanism operating by the Tau class glutathione transferases. Biochem J 2009; 422: 247-56.

[85] Skopelitou K, Muleta AW, Papageorgiou AC, Chronopoulou E, Labrou NE. Catalytic features and crystal structure of a tau class glutathione transferase from Glycine max specifically upregulated in response to soybean mosaic virus infections. Biochim Biophys Acta. 2014, 1854: 166-77. 
[86] Lallement PA, Meux E, Gualberto JM, et al. Structural and enzymatic insights into Lambda glutathione transferases from Populus trichocarpa, monomeric enzymes constituting an early divergent class specific to terrestrial plants. Biochem J 2014, 462: 39-52.

[87] Armstrong, RN. Structure, catalytic mechanism, and evolution of the glutathione transferases. Chem Res Toxicol 1997; 10: 2-18.

[88] Oakley AJ. Glutathione transferases: new functions. Curr Opin Struct Biol 2005; 15: 716-23.

[89] Prade L, Huber R, Bieseler B. Structures of herbicides in complex with their detoxifying enzyme glutathione S-transferase - explanations for the selectivity of the enzyme in plants. Structure 1998; 6: 1445-52.

[90] Sayed Y, Wallance LA, Dirr HW. The hydrophobic lock-and-key intersubunit motif of glutathione transferase A1-1: implications for catalysis, ligandin function and stability. FEBS Lett 2000; 465: 169-72.

[91] Hegazy UM, Mannervik B, Stenberg GJ. Functional role of the lock and key motif at the subunit interface of glutathione transferase P1-1. J Biol Chem 2004; 279: 9586-96.

[92] Vargo MA, Nguyen L, Colman RF. Subunit interface residues of glutathione S-transferase A1-1 that are important in the monomer-dimer equilibrium. Biochemistry 2004; 43: 3327-35.

[93] Hayes, JD, Pulford DJ. The glutathione S-transferase supergene family: regulation of GST and the contribution of the isoenzymes to cancer chemoprotection and drug resistance. Crit Rev Biochem Mol Biol 1995; 30: 445-600.

[94] Hayes JD, Flanagan JU, Jowsey IR. Glutathione transferases. Annu Rev Pharmacol Toxicol 2005; 45: 51-88.

[95] Axarli I, Georgiadou C, Dhavala P, Papageorgiou $\mathrm{AC}$, Labrou NE. Investigation of the role of conserved residues Ser13, Asn48 and Pro49 in the catalytic mechanism of the tau class glutathione transferase from Glycine max. Biochim Biophys Acta. 2010; 1804: 662-7.

[96] Dirr HW, Reinemer P, Huber R. X-ray crystal structures of cytosolic glutathione S-transferases. Implications for protein architecture, substrate recognition and catalytic function. Eur J Biochem 1994; 220: 645-61.

[97] Frova C. Glutathione transferases in the genomics era: New insights and perspectives. Biomol Eng 2006; 23: 149-69.

[98] Tang ZX, Yang HL. Functional divergence and catalytic properties of dehydroascorbate reductase family proteins from Populus tomentosa. Mol Biol Rep 2013; 40: 5105-14.

[99] Board PG, Menon D. Glutathione transferases, regulators of cellular metabolism and physiology. Biochim Biophys Acta. 2013; 1830: 3267-88.

[100] McTigue MA, Williams DR, Tainer JA. Crystal structures of a schistosomal drug and vaccine target: glutathione S-transferase from Schistosoma japonica and its complex with the leading antischistosomal drug praziquantel. J Mol Biol 1995; 246: 21-7.
[101] Oakley AJ, Lo Bello M, Nuccetelli M, Mazzetti AP, Parker MW. The ligandin (non-substrate) binding site of human Pi class glutathione transferase is located in the electrophile binding site (H-site). J Mol Biol 1999; 291: 913-26.

[102] Mueller L, Goodman CD, Silady RA, Walbot V. AN9, a petunia glutathione S-transferase required for anthocyanin sequestration, is a flavonoid-binding protein. Plant Physiol 2000; 123: 1561-70.

[103] Smith AP, Nourizadeh SD, Peer WA, et al. Arabidopsis AtGSTF2 is regulated by ethylene and auxin, and encodes a glutathione S-transferase that interacts with flavonoids. Plant J 2003; 36: 433-42.

[104] Axarli IA, Rigden DJ, Labrou NE. Characterization of the ligandin site of maize glutathione S-transferase I. Biochem J 2004; 382: 885-93.

[105] Hayeshi R, Chinyanga F, Chengedza S, Mukanganyama, S. Inhibition of human glutathione transferases by multidrug resistance chemomodulators in vitro. J Enzyme Inhib Med Chem 2006; 21: 581-87.

[106] Brock J, Board PG, Oakley AJ. Structural Insights into Omega-Class Glutathione Transferases: A Snapshot of Enzyme Reduction and Identification of a Non-Catalytic Ligandin Site. 2013; PLoS ONE [serial online]2013; 8: e60324. Available at: http://journals.plos.org/plosone/article?id=10.1371/jo urnal.pone.0060324 [accessed 9 April 2013].

[107] Reinemer P, Prade L, Hof P, et al. Three-dimensional structure of glutathione S-transferase from Arabidopsis thaliana at $2.2 \AA$ resolution: structural characterization of herbicide-conjugating plant glutathione Stransferases and a novel active site architecture. J Mol Biol 1996; 255: 289-309.

[108] Dixon DP, Sellars JD, Edwards R. The Arabidopsis phi class glutathione transferase AtGSTF2: binding and regulation by biologically active heterocyclic ligands. Biochem J 2011; 438: 63-70.

[109] Dixon DP, Edwards R. Selective binding of glutathione conjugates of fatty acid derivatives by plant glutathione transferases. J Biol Chem. 2009; 284: 21249-56.

[110] Lederer B, Böger P. A ligand function of glutathione S-transferase. Z Naturforsch C 2005; 60: 166-71.

[111] Dixon DP, Lapthorn A, Madesis P, Mudd EA, Day A, Edwards R. Binding and glutathione conjugation of porphyrinogens by plant glutathione transferases. J Biol Chem 2008; 283: 20268-76.

[112] Gill SS, Tuteja N. Reactive oxygen species and antioxidant machinery in abiotic stresstolerance in crop plants. Plant Physiol Biochem 2010; 48:909-30.

[113] Zhang Q, Xu F, Lambert KN, Riechers DE. Safeners coordinately induce the expression of multiple proteins and MRP transcripts involved in herbicide metabolism and detoxification in Triticum tauschii seedling tissues. Proteomics 2007; 7:1261-78.

[114] Yuan JS, Tranel PJ, Stewart CN, Jr. Non-target-site herbicide resistance: a family business. Trends Plant Sci 2007; 12: 6-13.

[115] Rea PA. Plant ATP-binding cassette transporters. Annu Rev Plant Biol 2007; 58: 347-75. 
[116] Schröder P. The role of glutathione and glutathione stransferase in plant reaction and adaptation to xenobiotics. In: Grill D, Tausz M, DeKok LJ, Eds. Significance of glutathione in plant adaptation to the environment. Dordrecht: Kluwer Academic Publishers, 2001: Pp. 155-83.

[117] Bartels D, Sunkar R. Drought and salt tolerance in plants. Crit Rev Plant Sci 2005; 24: 23-58.

[118] Dinlera BS, Antonioub C, Fotopoulos V. Interplay between GST and nitric oxide in the early response of soybean (Glycine max L.) plants to salinity stress. J. Plant Physiol 2014; 171:1740-47.

[119] Jolán Csiszár J, Horváth E, Váry Z, et al. Glutathione transferase supergene family in tomato: Salt stressregulated expression of representative genes from distinct GST classes in plants primed with salicylic acid. Plant Physiol Biochem 2014; 78:15-26.

[120] Yang G, Wang Y, Xia D, Gao C, Wang C, Yang C. Overexpression of a GST gene (ThGSTZ1) from Tamarix hispida improves drought and salinity tolerance by enhancing the ability to scavenge reactive oxygen species. Plant Cell Tiss Orga 2014; 117: 99-112.

[121] Rezaeia KM, Shobbara Z, Shahbazia M, Abedinia R, Zarea S. Glutathione S-transferase (GST) family in barley: Identification of members, enzyme activity, and gene expression pattern. J Plant Physiol 2013; 170: $1277-84$.

[122] Tripathi A, Indoliya Y, Tiwari M, et al. Transformed yeast (Schizosaccharomyces pombe) overexpressing rice Tau class glutathione S-transferase (OsGSTU30 and OsGSTU41) shows enhanced resistance to hexavalent chromium. Metallomics 2014; 6: 1549-57.

[123] Gunning V, Tzafestas $\mathrm{K}$, Sparrow $\mathrm{H}$, et al. Arabidopsis Glutathione Transferases U24 and U25 Exhibit a Range of Detoxification Activities with the Environmental Pollutant and Explosive, 2,4,6Trinitrotoluene1. Plant Physiol 2014; 165: 854-65.

[124] Chronopoulou E, Madesis P, Tsaftaris A, Labrou NE. Cloning and Characterization of a Biotic-StressInducible Glutathione Transferase from Phaseolus vulgaris Appl Biochem Biotechnol 2014; 172: 595609.

[125] Nakashima K, Ito Y, Yamaguchi-Shinozaki K. Transcriptional regulatory networks in response to abiotic stresses in Arabidopsis and grasses. Plant Physiol 2009; 149: 88-95.

[126] Bhatnagar-Mathur P, Vadez V, Sharma KK. Transgenic approaches for abiotic stress tolerance in plants: Retrospect and prospects. Plant Cell Rep 2008; 27: 411-24.

[127] Van Eck L, Davidson RM, Wu S, et al. The transcriptional network of WRKY53 in cereals links oxidative responses to biotic and abiotic stress inputs. Funct Integr Genomics. 2014; 14: 351-62.
[128] Van Der Zaal BJ, Droog FNJ, Pieterse FJ, Hooykaas PJJ. Auxin-sensitive elements from promoters of tobacco GST genes and a consensus as-1-like element differ only in relative strength. Plant Physiol 1996; 110: 79-88.

[129] Ulmasov T, Hagen G, Guilfoyle T. The ocs element in the soybean GH2/4 promoter is activated by both active and inactive auxin and salicylic acid analogues. Plant Mol Biol 1994; 26:1055-64.

[130] Takahashi Y, Sakai T, Ishida $S$, Nagata $T$. Identification of auxin-responsive elements of parB and their expression in apices of shoot and root. Proc Natl Acad Sci U S A 1995; 92:6359-63.

[131] Itzhaki H, Maxson JM, Woodson WR. An ethyleneresponsive enhancer element is involved in the senescence- related expression of the carnation glutathione-S-transferase (GST1) gene. Proc Natl Acad Sci U S A 1994; 91:8925-29.

[132] Csiszár J, Horváth E, Váry Z, et al. Glutathione transferase supergene family in tomato: Salt stressregulated expression of representative genes from distinct GST classes in plants primed with salicylic acid. Plant Physiol Biochem 2014; 78:15-26.

[133] Jain M, Ghanashyam C, Bhattacharjee A. Comprehensive expression analysis suggests overlapping and specific roles of rice glutathione Stransferase genes during development and stress responses. BMC Genomics [serial online]2010; 11:73. Available at: http://www.biomedcentral.com/14712164/11/73 [accessed 29 January 2010].

[134] Lan T, Yang ZL, Yang X, Liu YJ, Wang XR, Zenga QY. Extensive functional diversification of the populus glutathione s-transferase supergene family. Plant Cell 2009; 21:3749-66.

[135] Lamb C, Dixon RA. The oxidative burst in plant disease resistance, Annu Rev Plant Physiol Plant Mol Biol 1997; 48: 251-75.

[136] Dean JD, Goodwin PH, Hsiang T. Induction of glutathione S-transferasegenes of Nicotiana benthamiana following infection by Colletotrichum destructivum and $\mathrm{C}$. orbiculare and involvement of one in resistance. J Exp Bot 2005; 56: 1525-33.

[137] Liao W, Ji L, Wang J, et al. An Identification of glutathione S-transferase genes responding to pathogen infestation in Populus tomentosa. Funct Integr Genomics 2014; 14: 517-29.

[138] Hernández I, Chacón O, Rodriguez R, et al. Black shank resistant tobacco by silencing of glutathione Stransferase. Biochem Biophys Res Commun 2009; 387: 300-4.

[139] Chen IH, Chiu MH, Cheng SF, Hsu YH, Tsai CH. The glutathione transferase of Nicotiana benthamiana NbGSTU4 plays a role in regulating the early replication of Bamboo mosaic virus. New Phytol 2013; 199: 749-57. 